\title{
Prevalence of idiopathic hypercalciuria in children with urinary system related symptoms attending a pediatric hospital in Bandar Abbas in 2014
}

\author{
Maryam Esteghamati ${ }^{1}$, Kambiz Ghasemi ${ }^{1}$, Marie $\mathrm{Nami}^{2}$
}

${ }^{1}$ M.D., Assistant Professor of Pediatric Nephrology, Clinical Research Development Center of Children Hospital, Hormozgan University of Medical Sciences, Bandar Abbas, Iran

${ }^{2}$ M.D., General Physician, Infectious and Tropical Diseases Research Center, Hormozgan Health Institute, Hormozgan University of Medical Sciences, Bandar Abbas, Iran

\section{Type of article: Original}

\begin{abstract}
Background: Idiopathic hypercalciuria is a group of diseases which can be manifested with urinary symptoms. Its importance is due to high prevalence, recurrent infections, and stone formations which are often asymptomatic.

Objective: The objective of this study was to determine the prevalence of idiopathic hypercalciuria in children with urinary system related symptoms in Bandar Abbas in 2014.

Methods: This descriptive cross-sectional study was done in 2014 in a children's hospital in Bandar Abbas (southern Iran) on 321 children who were between 2 months to 14 years old. Random morning urine sample was obtained from all the patients, and calcium to creatinine ratio was assessed for all the patients for two times. Hypercalciuria is defined as urinary calcium excretion rate that is greater than $4 \mathrm{mg} / \mathrm{kg}$ per 24 hours in a child older than two years of age. Data was analyzed using IBM SPSS statistics 23.0 software and Chi-square and independent-samples t-test.

Results: Among the 321 children assessed, 153 (47.7\%) had idiopathic hypercalciuria. The mean age of the children with idiopathic hypercalciuria was $55.20 \pm 43.71$. Prevalence of idiopathic hypercalciuria was $48.3 \%$ in children with urinary tract infection, $54.9 \%$ and $53.6 \%$ in children with microscopic and macroscopic hematuria respectively, In children with dysuria, there were $52.1 \%$, and $51.8 \%$ in children with frequency, $49.1 \%$ in children with kidney stone which was confirmed with sonography, $28.6 \%$ and $37.5 \%$ in children with nocturnal and daily urinary incontinency respectively. Results of this study showed no significant relationship between urinary system symptoms and idiopathic hypercalciuria $(\mathrm{p}>0.05)$.

Conclusion: Hypercalciuria can be presented with different symptoms associated with urinary symptoms. Therefore, it is recommended to check the urinary calcium level in children with urinary symptoms with no definite etiology.

Keywords: Idiopathic hypercalciuria, Urinary symptoms, Children
\end{abstract}

\section{Introduction}

Hypercalciuria is one of the most common metabolic disorders (1) which can result in different urinary system symptoms (2). Idiopathic hypercalciuria is defined as increased urinary excretion of calcium in absence of hypercalcemia or any other etiologies for hypercalciuria (3). Its importance is for its high prevalence and its association with frequency, dysuria, proteinuria, and asymptomatic kidney stones (2). Idiopathic hypercalciuria is the most common cause of isolated hematuria in children and one important risk factor for kidney and urinary tract stones $(4,5)$. Also, idiopathic hypercalciuria is a risk factor for recurrent urinary tract infection which can be prevented via suitable diagnosis and treatment (6). Suitable treatment prevents stone formation and decrease of bone

\section{Corresponding author:}

Assistant Professor Dr. Maryam Esteghamati, Clinical Research Development Center of Children Hospital, Hormozgan University of Medical Sciences, Bandar Abbas, Iran.

Tel: +98.9123866020, Email: maryamesteghamati@yahoo.com

Received: November 23, 2015, Accepted: January 03, 2017, Published: September 2017

iThenticate screening: January 15, 2017, English editing: February 08, 2017, Quality control: July 28, 2017

(C) 2017 The Authors. This is an open access article under the terms of the Creative Commons Attribution-NonCommercialNoDerivs License, which permits use and distribution in any medium, provided the original work is properly cited, the use is non-commercial and no modifications or adaptations are made. 
density in both children and adults (7-9). Prevalence of idiopathic hypercalciuria depends on different factors such as geographical areas, nutritional variables, climate, and genetic factors, and is variable between $2.9 \%$ to $10 \%(9$, 10). Prevalence of idiopathic hypercalciuria is variable in different countries. Idiopathic hypercalciuria is associated with higher risk of renal stones among affected children (11). Idiopathic hypercalciuria has also high prevalence among children with urinary symptoms. Balestracci et al. have reported the prevalence of 20\% for idiopathic hypercalciuria among children with urinary tract infection (12). Also, the association of idiopathic hypercalciuria and reduced bone mineral density is suggested by some researchers $(13,14)$. It is shown that dietary interventions may reduce the complications of idiopathic hypercalciuria (15). Therefore, it is important to diagnose it in children, and epidemiologic information about the disease is helpful. No information is available about the prevalence of idiopathic hypercalciuria in Bandar Abbas. The general objective of this study was to determine the prevalence of idiopathic hypercalciuria in children with urinary symptoms referred to a children's hospital in Bandar Abbas.

\section{Material and Methods}

This descriptive cross sectional study was carried out in a children's hospital in Bandar Abbas. All children attending our pediatric nephrology clinic who had urinary symptoms were included in our study using convenience sampling during a one year period. We enrolled 321 children between 2 months to 14 years old during 2013 and 2014, who were referred for outpatient visit or hospitalization with urinary symptoms including dysuria, frequency, urinary tract infection, macroscopic and microscopic hematuria, nocturnal and daily urinary incontinency and kidney stones confirmed with sonography. Patients who were using nephrotoxic drugs, corticosteroids, vitamin D, or methylxanthines for causes other than urinary symptoms such as kidney diseases, liver and biliary tract diseases were excluded from the study. Before starting the study, a written informed consent was obtained from the parents of all the children. Random morning urine samples were obtained from all the patients for measurement of $\mathrm{Ca} / \mathrm{Cr}$ levels for two times. Idiopathic hypercalciuria was defined as 24 hours' urine calcium more than $4 \mathrm{mg} / \mathrm{kg}$ or $\mathrm{Ca} / \mathrm{Cr}$ level more than 0.2 or more than 0.8 in less than 7 months old children. For all the patients, a checklist was completed for demographic variables including: age, sex, and place of residence. Also, the information for different urinary symptoms was recorded. Data was analyzed using IBM SPSS statistics 23 software and was analyzed using descriptive statistics (mean and standard deviation, and frequency) and Chi-Square and independent samples $\mathrm{t}$ test. $\mathrm{P}$ values less than 0.05 were assumed to be significant.

\section{Results}

We studied 321 children including 166 (51.7\%) males and 155 (48.3\%) females with average age of 51.62 \pm 41.08 months. Among the children studied, 153 (47.7\%) had idiopathic hypercalciuria, including $82(53.6 \%)$ males and 71 $(46.6 \%)$ females with average age of $55.20 \pm 43.71$ months.

Table 1. Frequency of idiopathic hypercalciuria in children with urinary symptoms

\begin{tabular}{|c|c|c|c|c|}
\hline \multicolumn{2}{|l|}{ Urinary system symptoms } & $\begin{array}{l}\text { Idiopathic hypercalciuria; } n \\
(\%)\end{array}$ & $\begin{array}{l}\text { No idiopathic hypercalciuria; } \\
\mathrm{n}(\%)\end{array}$ & p-value \\
\hline \multirow[t]{2}{*}{ Urinary tract infection } & Yes & $115(48.3)$ & $123(51.7)$ & \multirow[t]{2}{*}{0.690} \\
\hline & No & $38(45.8)$ & $45(54.2)$ & \\
\hline \multirow[t]{2}{*}{ Microscopic hematuria } & Yes & $28(54.9)$ & $23(45.1)$ & \multirow[t]{2}{*}{0.259} \\
\hline & No & $125(46.3)$ & $145(53.7)$ & \\
\hline \multirow[t]{2}{*}{ Macroscopic hematuria } & Yes & $15(53.6)$ & $13(46.4)$ & \multirow[t]{2}{*}{0.512} \\
\hline & No & $138(47.1)$ & $155(52.9)$ & \\
\hline \multirow[t]{2}{*}{ Dysuria } & Yes & $50(52.1)$ & $46(47.9)$ & \multirow[t]{2}{*}{0.300} \\
\hline & No & $103(45.8)$ & $122(54.2)$ & \\
\hline \multirow[t]{2}{*}{ Frequency } & Yes & $43(51.8)$ & $40(48.2)$ & \multirow[t]{2}{*}{0.380} \\
\hline & No & $110(46.2)$ & $128(53.8)$ & \\
\hline \multirow[t]{2}{*}{ Kidney stone } & Yes & $28(49.1)$ & $29(50.9)$ & \multirow[t]{2}{*}{0.808} \\
\hline & No & $125(47.3)$ & $139(52.7)$ & \\
\hline \multirow{2}{*}{$\begin{array}{l}\text { Nocturnal urinary } \\
\text { incontinency }\end{array}$} & Yes & $4(28.6)$ & $10(71.4)$ & \multirow[t]{2}{*}{0.144} \\
\hline & No & $149(48.5)$ & $158(51.5)$ & \\
\hline \multirow[t]{2}{*}{ Daily urinary incontinency } & Yes & $3(37.5)$ & $5(62.5)$ & \multirow[t]{2}{*}{0.560} \\
\hline & No & $150(47.9)$ & $163(52.1)$ & \\
\hline
\end{tabular}


After clinic and laboratory tests, urinary tract infection was confirmed in 238 (74.1\%), among which, 115 (48.3\%) had idiopathic hypercalciuria, including 56 males and 59 females. Also, 51 (15.9\%) had microscopic hematuria and $28(8.7 \%)$ had macroscopic hematuria. Among them, 28 (54.9\%) and 15 (53.6\%) had idiopathic hypercalciuria respectively. Dysuria was reported in $96(29.9 \%)$ of the children in this study, among which, $50(52.1 \%)$ had idiopathic hypercalciuria. Ultrasound sonography showed kidney stones in 57 (17.8\%) including 43 (51.8\%) children with idiopathic hypercalciuria. Among the children in our study, 14 (4.4\%) had nocturnal urinary incontinency, and $8(2.5 \%)$ had daily urinary incontinency among which $4(28.6 \%)$ and $3(37.5 \%)$ had idiopathic hypercalciuria respectively. There was no significant relationship between urinary tract infection, hematuria, dysuria, frequency, kidney stone, daily and nocturnal urinary incontinency, and idiopathic hypercalciuria ( $>0.05$ ). Details are shown in Table 1.

\section{Discussion}

In this study, we assessed the frequency of idiopathic hypercalciuria in children between 2 months to 14 years old with various urinary symptoms. Some studies have selected their samples from children with confirmed idiopathic hypercalciuria, and have reported the prevalence of different symptoms related to the urinary system in these patients. Both study designs are able to show the importance of urinary system related symptoms in children with idiopathic hypercalciuria. Assessment of 24-hour urine calcium level is difficult in children and we have used urine $\mathrm{Ca} / \mathrm{Cr}$ level in random morning sample in study participants, which is shown to be accurate enough, and has specificity and sensitivity of more than $90 \%$. In our study the prevalence of idiopathic hypercalciuria was very high, and was more frequent among children with microscopic hematuria (54.9\%) and less frequent among children with nocturnal urinary incontinency (28.6\%). In this study, we found no significant relationship between different urinary systems related symptoms and prevalence of idiopathic hypercalciuria. High difference in the prevalence of idiopathic hypercalciuria in our study and similar studies in Ahwaz (16), and Tehran (17) which have reported the prevalence of $3 \%$ and $5.4 \%$ respectively, can be due to difference in climate, study designs and data collections. Although in the current study, the prevalence of idiopathic hypercalciuria was higher (53.6\%) among males, but the difference in prevalence of idiopathic hypercalciuria according to gender was not statistically significant. Moore et al. (9) and Ahmadzadeh et al. have reported higher prevalence of idiopathic hypercalciuria among males, but higher prevalence of idiopathic hypercalciuria is reported among females $(42.9 \%$ versus $17.1 \%)$ in the study by Sadeghi et al. (18). Prevalence of dysuria, frequency, microscopic and macroscopic hematuria, kidney stone, and urinary tract infection were higher in the current study, in comparison to the study in Shiraz $(19)(18,19)$, but the prevalence of daily and nocturnal urinary incontinency was similar in these studies. In a study in 2001 Maria Goretti et al. reported the prevalence of $31 \%$ for hematuria, among the patients with idiopathic hypercalciuria, which is lower than our study (20). Also, the prevalence of kidney stones was $56 \%$ in the study by Goretti et al. and $49.1 \%$ in our study. In a study in 2004 Biyikli et al. reported idiopathic hypercalciuria in about $43 \%$ of children over 5 years old, with recurrent urinary tract infections (21). This rate was $48.3 \%$ in our study. One study in 2006 reported the prevalence of $21 \%$ for idiopathic hypercalciuria among the children with urinary tract infection (22), which is lower that our study.

\section{Conclusions}

Based on the results of our study and similar studies, the prevalence of idiopathic hypercalciuria is high among children with urinary symptoms. The importance of our findings is that idiopathic hypercalciuria should be considered as an important cause of urinary symptoms in children when other causes are less probable. Also, we recommend that the children with urinary symptoms with no definite etiology should be screened for idiopathic hypercalciuria. More studies are recommended in different areas, because the prevalence of idiopathic hypercalciuria is variable, based on the place of residence and nutritional status.

\section{Acknowledgments:}

This paper is prepared based on the results of a medical student thesis which is approved and done in Hormozgan University of Medical Sciences (HUMS). The authors want to thank the research committee for their support for doing this research.

\section{Conflict of Interest:}

There is no conflict of interest to be declared.

\section{Authors' contributions:}

All authors contributed to this project and article equally. All authors read and approved the final manuscript. 


\section{References:}

1) Weir MR. Atypical idiopathic hypercalciuria in an adolescent. J Adolesc Health Care. 1988; 9(6): 498-500. doi: 10.1016/S0197-0070(88)80010-X. PMID: 3182367.

2) Heiliczer JD, Canonigo BB, Bishof NA, Moore ES. Noncalculi urinary tract disorders secondary to idiopathic hypercalciuria in children. Pediatr Clin North Am. 1987; 34(3): 711-8. doi: 10.1016/S00313955(16)36263-0. PMID: 3295723.

3) Langman CB, Moore ES. Hypercalciuria in clinical pediatrics. A review. Clin Pediatr (Phila). 1984; 23(3): 135-7. doi: 10.1177/000992288402300301. PMID: 6365401.

4) Letavernier E, Traxer O, Daudon M, Tligui M, Hubert-Brierre J, Guerrot D, et al. Determinants of osteopenia in male renal-stone-disease patients with idiopathic hypercalciuria. Clin J Am Soc Nephrol. 2011; 6(5): 1149-54. doi: 10.2215/CJN.10191110. PMID: 21441130, PMCID: PMC3087782.

5) Cioppi F, Taddei L, Brandi ML, Croppi E. Idiopathic hypercalciuria and calcium renal stone disease: our cases. Clin Cases Miner Bone Metab. 2009; 6(3): 251-3. PMID: 22461254, PMCID: PMC2811358.

6) Lopez MM, Castillo LA, Chavez JB, Ramones C. Hypercalciuria and recurrent urinary tract infection in Venezuelan children. Pediatr Nephrol. 1999; 13(5): 433-7. doi: 10.1007/s004670050635. PMID: 10412865.

7) Garcia CD, Miller LA, Stapleton FB. Natural history of hematuria associated with hypercalciuria in children. Am J Dis Child. 1991; 145(10): 1204-7. doi: 10.1001/archpedi.1991.02160100136039. PMID: 1928018.

8) Polito C, Iolascon G, Nappi B, Andreoli S, La Manna A. Growth and bone mineral density in long-lasting idiopathic hypercalciuria. Pediatr Nephrol. 2003; 18(6): 545-7. doi: 10.1007/s00467-003-1137-x. PMID: 12698330 .

9) Moore ES, Coe FL, McMann BJ, Favus MJ. Idiopathic hypercalciuria in children: prevalence and metabolic characteristics. J Pediatr. 1978; 92(6): 906-10. doi: 10.1016/S0022-3476(78)80358-8. PMID: 660355.

10) Escribano J, Balaguer A, Martin R, Feliu A, Espax R. Childhood idiopathic hypercalciuria--clinical significance of renal calyceal microlithiasis and risk of calcium nephrolithiasis. Scand J Urol Nephrol. 2004; 38(5): 422-6. doi: 10.1080/00365590410033434. PMID: 15764255.

11) Coe FL, Worcester EM, Evan AP. Idiopathic hypercalciuria and formation of calcium renal stones. Nat Rev Nephrol. 2016; 12(9): 519-33. doi: 10.1038/nrneph.2016.101. PMID: 27452364.

12) Balestracci A, Battaglia LM, Toledo I, Martin SM, Wainsztein RE. Idiopathic hypercalciuria in children with urinary tract infection. Arch Argent Pediatr. 2014; 112(5): 428-33. doi: 10.1590/S032500752014000500007. PMID: 25192523.

13) Artemiuk I, Panczyk-Tomaszewska M, Adamczuk D, Przedlacki J, Roszkowska-Blaim M. Bone Mineral Density in Children with Idiopathic Hypercalciuria. Dev Period Med. 2015; 19 (3 Pt 2): 356-61. PMID: 26958681.

14) Escribano J, Rubio-Torrents C, Ferre N, Luque V, Grote V, Zaragoza-Jordana M, et al. Reduced bone mass in 7-year-old children with asymptomatic idiopathic hypercalciuria. Ann Nutr Metab. 2014; 64(3-4): 30413. doi: 10.1159/000365038. PMID: 25300274.

15) Escribano J, Balaguer A, Roque I, Figuls M, Feliu A, Ferre N. Dietary interventions for preventing complications in idiopathic hypercalciuria. Cochrane Database Syst Rev. 2014; 11(2): CD006022. doi: 10.1002/14651858.CD006022.pub4. PMID: 24519664.

16) Ahmadzadeh $A$, Hakimzadeh $M$, Safa-Abadi A. Idiopathic hypercalciuria in Iranian children. Iranian Journal of Pediatrics. 2008; 18(2): 163-6.

17) Esfahani ST, Madani A, Siadati AA, Nabavi M. Prevalence and symptoms of idiopathic hypercalciuria in primary school children of Tehran. Iran J Pediatr. 2007; 17: 353-8.

18) Sadeghi-Bojd S, Hashemi M. Hypercalciuria and recurrent urinary tract infections among children in Zahedan, Iran. J Pak Med Assoc. 2008; 58(11): 624-6. PMID: 19024135.

19) Fallahzadeh MK, Fallahzadeh MH, Mowla A, Derakhshan A. Hypercalciuria in children with urinary tract symptoms. Saudi J Kidney Dis Transpl. 2010; 21(4): 673-7. PMID: 20587871.

20) Penido MG, Diniz JS, Moreira ML, Tupinamba AL, Franca A, Andrade BH, et al. [Idiopathic hypercalciuria: presentation of 471 cases]. J Pediatr (Rio J). 2001; 77(2): 101 -4. PMID: 14647599.

21) Biyikli NK, Alpay H, Guran T. Hypercalciuria and recurrent urinary tract infections: incidence and symptoms in children over 5 years of age. Pediatr Nephrol. 2005; 20(10): 1435-8. doi: 10.1007/s00467005-1892-y. PMID: 16047226.

22) Stojanovic VD, Milosevic BO, Djapic MB, Bubalo JD. Idiopathic hypercalciuria associated with urinary tract infection in children. Pediatr Nephrol. 2007; 22(9): 1291-5. doi: 10.1007/s00467-007-0519-x. PMID: 17541648 . 